\title{
QUALIDADE FISIOLÓGICA E SANITÁRIA DE SEMENTES DE PIMENTÃO COMERCIALIZADAS EM SANTARÉM, PARÁ
}

\author{
Bruna Nayara Pantoja Vieira'; Bruno Rodrigo dos Santos²; Bruna Cristine Martins de Sousa ${ }^{3}$; Thiago \\ Almeida Vieira4; Denise Castro Lustosa ${ }^{5}$.

\footnotetext{
1 Universidade Federal do Oeste do Pará, Santarém, Pará, Brasil, brunavieiraagro@gmail.com

2 Universidade Federal do Oeste do Pará, Santarém, Pará, Brasil, bruno.rjdossantos@gmail.com

3 Universidade Federal do Oeste do Pará, Santarém, Pará, Brasil, bruna0909martins@hotmail.com

${ }^{4}$ Universidade Federal do Oeste do Pará, Santarém, Pará, Brasil, thiago.vieira@ufopa.edu.br

${ }^{5}$ Universidade Federal do Oeste do Pará, Santarém, Pará, Brasil, denise.lustosa@ufopa.edu.br
}

RESUMO: A qualidade das sementes é um dos aspectos mais importantes para se alcançar o sucesso da lavoura. Nesse sentindo, objetivou-se com este trabalho avaliar a qualidade fisiológica e sanitária de sete cultivares de pimentão (Capsicum annuum L.) comercializadas em Santarém, Pará. As sementes foram distribuídas, equidistantemente, em caixas plásticas do tipo gerbox ${ }^{\circledR}$ contendo papel filtro esterilizado e umedecido, e mantidas a $\pm 25^{\circ} \mathrm{C}$ durante 14 dias com fotoperíodo de 12h. Foram avaliados a germinação, o número de plântulas normais e anormais aos sete e 14 dias, índice de velocidade de germinação (IVG) e incidência de fungos sobre as sementes. O delineamento experimental foi inteiramente casualizado, com quatro repetições, sendo 50 sementes por repetição, perfazendo um total de 1400 sementes avaliadas. Todos os lotes das cultivares de pimentão avaliados exibiram baixo vigor, considerando-se a baixa porcentagem de plântulas normais resultantes. Os lotes das cultivares All Big, Amarelo SF 134, Quadrado Vermelho e Rubi Gigante apresentaram germinação dentro dos padrões informados pelos fabricantes. Nas sementes de Amarelo SF 134 e Itapuã 501 observou-se 100\% de incidência fúngica, sendo identificados os gêneros Aspergillus, Fusarium, Penicillium e Rhizopus. Itapuã 501 apresentou o pior desempenho fisiológico e sanitário dentre os lotes das cultivares avaliadas. Considerando-se a baixa porcentagem de plântulas normais resultantes, os lotes das cultivares de pimentão avaliados nesse trabalho poderiam comprometer o estande inicial do plantio.

PALAVRAS-CHAVE: Capsicum annuum, Germinação, Patologia de sementes, Vigor. 


\title{
PHYSIOLOGICAL AND SANITARY QUALITY OF PEPPER SEEDS COMMERCIALIZED IN SANTARÉM, PA
}

\begin{abstract}
The physiological and sanitary quality of seeds is one of the most important aspects to achieve crop success. In this sense, the objective of this work was to evaluate the physiological and sanitary quality of seven cultivars of pepper (Capsicum annuum L.) commercialized in Santarém, Pará. The seeds were distributed equidistantly in gerbox ${ }^{\circledR}$ plastic boxes containing sterilized and moistened filter paper and maintained at $\pm 25^{\circ} \mathrm{C}$ for 14 days with $12 \mathrm{~h}$ photoperiod. Germination, number of normal and abnormal seedlings at seven and 14 days, germination speed index (IVG) and fungi incidence on the seeds were evaluated. The experimental design was completely randomized, with four replicates, 50 seeds per replicate, making a total of 1400 seeds evaluated. All the lots of the evaluated pepper cultivars exhibited low vigor, considering the low percentage of normal seedlings resulting. The lots of the cultivars All Big, Yellow SF 134, Red Square and Ruby Giant presented germination within the standards informed by the manufacturers. In the seeds of Yellow SF 134 and Itapuã 501 100\% of fungal incidence was observed, being identified the genera Aspergillus, Fusarium, Penicillium and Rhizopus. Itapuã 501 presented the worst physiological and sanitary performance among the lots of the evaluated cultivars. Considering the low percentage of normal seedlings resulting, the plots of the pepper cultivars evaluated in this work could compromise the initial planting stand.
\end{abstract}

KEYWORDS: Capsicum annuum, Germination, Seed pathology, Vigor.

\section{CALIDAD FISIOLÓGICA Y SANITARIA DE SEMILLAS DE PIMIENTO COMERCIALIZADAS EN SANTARÉM, PA}

RESUMEN: La calidad fisiológica y sanitaria de las semillas es uno de los aspectos más importantes para alcanzar el éxito del cultivo. En ese sentido, el trabajo objetivó evaluar la calidad fisiológica y sanitaria de siete cultivares de pimiento (Capsicum annuum L.) comercializadas en Santarém, Pará. Las semillas fueron distribuidas equidistantemente en cajas plásticas del tipo gerbox ${ }^{\circledR}$ conteniendo papel filtro esterilizado y humedecido, y mantenidas a $\pm 25^{\circ} \mathrm{C}$ durante 14 días con fotoperíodo de $12 \mathrm{~h}$. Se evaluaron la germinación, el número de plántulas normales y anormales a los siete y 14 días, índice de velocidad de germinación (IVG) e incidencia de hongos sobre las semillas. El delineamiento experimental fue completamente casualizado, con cuatro repeticiones, siendo 50 semillas por repetición, totalizando un total de 1400 semillas evaluadas. Todos los lotes de los cultivares de pimiento evaluados exhibieron bajo vigor, considerando el bajo porcentaje de plántulas normales 
resultantes. Los lotes de los cultivares All Big, Amarillo SF 134, Cuadrado Rojo y Rubí Gigante presentaron germinación dentro de los estándares informados por los fabricantes. En las semillas de Amarillo SF 134 e Itapuã 501 se observó un 100\% de incidencia fúngica, siendo identificados los géneros Aspergillus, Fusarium, Penicillium y Rhizopus. Itapuã 501 presentó el peor desempeño fisiológico y sanitario entre los lotes de los cultivares evaluados. Se consideró el bajo porcentaje de plántulas normales resultantes, los lotes de los cultivares de pimiento evaluados en ese trabajo podrían comprometer el stand inicial de la siembra.

PALABRAS CLAVE: Capsicum annuum, Germinación, Patología de semillas, Vigor.

\section{- pimentão (Capsicum}

annuum L.) encontra-se entre as 10 hortaliças de maior importância econômica e social, tendo grande participação na culinária doméstica e empresarial, bem como na geração de emprego (PEREIRA et al., 2013).

Devido a propagação do pimentão ser feita por meio de sementes, o controle sanitário e fisiológico apresenta grande importância para o sucesso de um bom estande e consequentemente de produtividade (POSSE et al., 2004). A qualidade de um lote de sementes para semeadura é determinada pelo somatório de atributos genéticos, fisiológicos, sanitários e físicos (COSTA, 2008). atributo genético refere-se às características intrínsecas da cultivar, como seu potencial produtivo, resistência a pragas e doenças, arquitetura da planta, entre outras; o atributo físico está associado à pureza do lote e a condição física da semente, que abrange o teor de umidade, tamanho, cor, formato e densidade uniformes, enquanto que, o componente fisiológico está associado à longevidade da semente e a sua capacidade de gerar uma planta com vigor e uniforme, sendo influenciado pelo ambiente em que se formam as sementes e pelas condições de colheita, secagem, beneficiamento e armazenagem (TALAMINI et al., 2010).

A queda do poder germinativo e do vigor pode ser causada por 
patógenos associados às sementes (TALAMINI et al., 2010), sendo os fungos os organismos mais importantes que as infectam, responsáveis pela disseminação de doenças, apodrecimento das sementes no solo, deterioração durante $\mathrm{o}$ armazenamento e produção de micotoxinas (DHINGRA; ACUNA, 1997). Nesse sentido, o trabalho objetivou avaliar a qualidade sanitária e fisiológica de lotes de sementes de pimentão, comercializadas em Santarém, PA.
O trabalho foi conduzido no Laboratório de Fitopatologia, do Instituto de Biodiversidade e Floresta IBEF, na Universidade Federal do Oeste do Pará - UFOPA. Foram avaliados lotes de sementes de sete cultivares de pimentão, comercializados em Santarém, PA, pertencentes a três produtoras de sementes. As informações das sementes fornecidas pelos fabricantes, contidas nas embalagens, encontramse na Tabela 1.

Tabela 1. Informações contidas nas embalagens dos lotes das cultivares de pimentão comercializadas em Santarém, PA e avaliadas no trabalho.

\begin{tabular}{lccccc}
\hline Cultivares & Produtora & $\begin{array}{c}\text { Germinaçã } \\
\text { o }(\%)\end{array}$ & $\begin{array}{c}\text { Pureza } \\
(\%)\end{array}$ & $\begin{array}{c}\text { Revestiment } \\
\text { o }\end{array}$ & $\begin{array}{c}\text { Validade } \\
\text { do lote }\end{array}$ \\
\hline All Big & 1 & 98,0 & 100,0 & Sim & $05 / 2018$ \\
Amarelo SF 134 & 1 & 98,0 & 100,0 & Não & $09 / 2018$ \\
Casca Dura lkeda & 1 & 89,0 & 100,0 & Sim & $01 / 2018$ \\
Rubi Gigante & 1 & 95,0 & 99,7 & Sim & $05 / 2018$ \\
Yolo Wonder & 1 & 70,0 & 99,9 & Sim & $02 / 2018$ \\
Quadrado & 2 & 85,0 & 99,0 & Não & $07 / 2018$ \\
Vermelho & 3 & 80,0 & 100,0 & Não & $04 / 2017$ \\
Itapuã 501 & & & &
\end{tabular}


Para avaliação da qualidade fisiológica e sanitária dos lotes das cultivares de pimentão, as sementes foram depositadas equidistantemente, em caixas plásticas do tipo gerbox ${ }^{\circledR}$ contendo duas folhas de papel filtro esterilizadas, umedecidas com água destilada esterilizada na quantidade equivalente a 2,5 vezes o peso do papel e mantidas a $\pm 25^{\circ} \mathrm{C}$ com fotoperíodo de 12h. O delineamento experimental foi inteiramente casualizado (DIC), com quatro repetições, contendo 50 sementes, sendo 200 sementes por cultivar, totalizando 1400 sementes no ensaio.

Foram avaliados: germinação, plântulas normais e anormais, índice de velocidade de germinação (IVG) e incidência de fungos. As avaliações de germinação, plântulas normais e anormais foram realizadas aos sete e 14 dias após a semeadura. A classificação de plântulas normais e anormais foi realizada conforme proposto pelas Regras para Análise de Sementes - RAS (BRASIL, 2009).
A porcentagem de plântulas normais obtida na avaliação do teste de germinação, na primeira contagem aos sete dias, foi utilizada para determinar o vigor das sementes, que foi interpretado de acordo com a classificação adaptada por Vieira e Carvalho (1994), onde: a) vigor muito alto: superior a 80\%; b) vigor alto: entre 70 a 79\%; c) vigor médio: entre 50 a 69\%; d) vigor baixo: entre 30 a 49\% e, e) vigor muito baixo: inferior a 29\%.

O índice de velocidade de germinação (IVG) foi obtido por meio da contagem diária de sementes germinadas até a estabilização da germinação (considerada estável após três leituras constantes) e aplicação da fórmula proposta por Maguire (1962).

Ao final do teste de germinação, avaliou-se a incidência de fungos sobre as sementes, examinando-as, sob microscópio estereoscópio, e contando-se aquelas que apresentavam estruturas fúngicas na sua superfície, calculando-se ao final, a porcentagem de contaminação. 
Para obtenção da distribuição normal dos dados foram realizadas as seguintes transformações: raiz $(x+1)$ para plântulas normais; raiz (x) para plântulas anormais e, $\operatorname{arcsen} \sqrt{ } \times / 100$ para germinação, conforme recomendação de Ferreira (2000). Para análise estatística, utilizou-se o software Assistat $^{\circledR} 7.7$ Beta, comparando-se as médias dos tratamentos pelo teste de Tukey a 5\% de probabilidade. Para melhor visualização, os dados de germinação e, plântulas normais e anormais foram apresentados na tabela sem a transformação.

Houve diferença significativa para todas as variáveis analisadas $(p<0,01)$. As cultivares All Big, Amarelo SF 134, Quadrado Vermelho e Rubi Gigante, apresentaram porcentagem de germinação acima de 90\% (Tabela 2), resultado semelhante ao fornecido pelo fabricante (Tabela 1). Torres e Ninami (2000), em ensaios com a cultivar All Big, obtiveram 74 a 89\% de germinação. Na cultivar Itapuã 501 apenas 7\% das sementes germinaram
(Tabela 2), diferindo do informado na embalagem (80\%).

Na avaliação de plântulas normais, aos sete dias, todas as cultivares avaliadas apresentaram vigor muito baixo, de acordo com a classificação de Vieira e Carvalho (1994). Somente em Amarelo SF 134 foram observadas plântulas normais, mas apenas 1\% delas. Resultados diferentes foram encontrados por Torres e Minami (2000) que avaliando sementes de pimentão da cultivar All Big, obtiveram 41 a 71\% de plântulas normais e, por Oliveira e Novembre (2005) que em experimentos com pimentão, obtiveram valores variando entre 45 e 78\% para essa variável.

Na avaliação aos 14 dias, apenas quatro das sete cultivares avaliadas apresentaram plântulas normais. No entanto, baixa porcentagem, variando de 2,5\% a 13\% (Tabela 2), sendo classificadas com vigor baixo e vigor muito baixo. Em Casca Dura Ikeda, Itapuã 501 e Yolo Wonder todas as sementes germinadas originaram plântulas anormais (Tabela 2). Franzin 
e Roversi (2002) afirmam que, sob condições de campo, plântulas anormais teriam poucas condições de se desenvolverem e tornarem plantas produtivas. França-Neto et al. (2010) acrescentam que sementes com vigor médio ou baixo em condições de estresses podem sofrer mais consequências resultando em baixa produtividade.

As cultivares Amarelo SF 134, All Big, Quadrado Vermelho e Rubi Gigante apresentaram maiores índices de velocidade de germinação, não diferindo entre si. (Tabela 2). Silva e Vieira (2006) observaram que cultivares de beterraba que apresentaram maior velocidade de germinação foram mais vigorosas, havendo, portanto, relação direta entre velocidade de germinação e vigor das sementes para essa cultivar avaliada.

De acordo com o informado nas embalagens, as sementes das cultivares Itapuã e Yolo Wonder, que resultaram nos menores IVG, apresentavam porcentagens de germinação abaixo das demais cultivares, além da cultivar
Yolo Wonder ser revestida. Pereira et al. (2005) verificaram que, em relação ao IVG, sementes de pimentão não revestidas germinaram mais rápido do que as revestidas e, Oliveira et al. (2003) também obtiveram resultado semelhante com sementes de tomates revestidas.

Nas cultivares de pimentão avaliadas, cujas sementes não foram revestidas (Amarelo SF 134, Itapuã 501 e Quadrado Vermelho), ocorreram as maiores incidências de fungos, sendo que, em Amarelo SF 134 e Itapuã 501 observou-se $100 \%$ de incidência (Tabela 2). A alta ocorrência de fungos nas sementes não comprometeu a germinação de Amarelo SF 134, mas afetou negativamente as sementes da cultivar Itapuã 501. Para Aimi et al. (2016), a avaliação da qualidade sanitária serve para comparar a qualidade de diferentes lotes de sementes e sua utilização comercial; dessa forma, para diminuir ou mesmo erradicar os organismos patogênicos presentes nas sementes, é viável a utilização de tratamento. Segundo 
Talamini et al. (2010), fungos de sobrevivência do fungo e sua armazenamento podem promover disseminação. Ruiz Filho et al. (2004) enfraquecimento ou morte do expõem que, muitos fungos em embrião, reduzindo a germinação e sementes estão associados à sua emergência das sementes.

Botelho et al. (2008) relatam que nem sempre a associação de fungos com sementes acarreta doença ou queda na qualidade fisiológica; porém, essa associação pode favorecer a deterioração e, sua ação é dependente das condições físicas e fisiológicas das mesmas, por ocasião da armazenagem, e dos fatores ambientais predominantes no decorrer desse período.

Tabela 2. Qualidade fisiológica e sanitária de sete cultivares de pimentão (Capsicum annuum L.), comercializadas em Santarém, PA, determinada pelo índice de velocidade de germinação (IVG), germinação, plântulas normais e anormais e incidência de fungos, aos 14 dias após a montagem do ensaio.

\begin{tabular}{lccccc}
\hline & \multicolumn{4}{c}{ Qualidade Fisiológica } & $\begin{array}{c}\text { Qualidade } \\
\text { Sanitária }\end{array}$ \\
\cline { 2 - 6 } Cultivares de Pimentão & $\begin{array}{c}\text { Germinação } \\
(\%)\end{array}$ & IVG & $\begin{array}{c}\text { Plântulas } \\
\text { Normais } \\
(\%)\end{array}$ & $\begin{array}{c}\text { Plântulas } \\
\text { Anormais } \\
(\%)\end{array}$ & $\begin{array}{c}\text { Incidência } \\
\text { de Fungos } \\
(\%)\end{array}$ \\
\hline All Big & $91,0 \mathrm{a}$ & $35,6 \mathrm{ab}$ & $6,5 \mathrm{ab}$ & $84,5 \mathrm{ab}$ & $18,0 \mathrm{c}$ \\
Amarelo SF 134 & $93,0 \mathrm{a}$ & $46,1 \mathrm{a}$ & $2,5 \mathrm{bc}$ & $90,5 \mathrm{a}$ & $100,0 \mathrm{a}$ \\
Casca Dura Ikeda & $63,0 \mathrm{~b}$ & $30,7 \mathrm{~b}$ & $0,0 \mathrm{c}$ & $63,0 \mathrm{~b}$ & $16,0 \mathrm{c}$ \\
Itapuã 501 & $7,0 \mathrm{~d}$ & $3,0 \mathrm{c}$ & $0,0 \mathrm{c}$ & $7,0 \mathrm{~d}$ & $100,0 \mathrm{a}$ \\
Quadrado Vermelho & $96,0 \mathrm{a}$ & $41,6 \mathrm{ab}$ & $3,0 \mathrm{abc}$ & $93,0 \mathrm{a}$ & $43,0 \mathrm{~b}$ \\
Rubi Gigante & $95,0 \mathrm{a}$ & $45,1 \mathrm{ab}$ & $13,0 \mathrm{a}$ & $82,0 \mathrm{ab}$ & $7,0 \mathrm{c}$ \\
Yolo Wonder & $31,0 \mathrm{c}$ & $12,8 \mathrm{c}$ & $0,0 \mathrm{c}$ & $31,0 \mathrm{c}$ & $16,0 \mathrm{c}$ \\
\hline CV(\%) & 9,0 & 21,0 & 19,9 & 8,0 & 18,8 \\
\hline
\end{tabular}

*Médias seguidas pelas mesmas letras nas colunas não diferem entre si pelo teste de Tukey $(p<0,01)$.

Os gêneros fúngicos Rhizopus (Figura 1). Aspergillus e encontrados nas sementes foram Penicillium são considerados fungos Aspergillus, Fusarium, Penicillium e típicos de armazenamento e podem 
causar depreciação de grãos ou sementes, principalmente quando armazenadas sob condições inadequadas (TALAMINI et al., 2010; RUIZ FILHO et al., 2004). Resultados diferentes foram encontrados por
Kikuti et al. (2005) trabalhando com cinco lotes de sementes de pimentão submetidas ou não à assepsia, nos quais não foram detectados os fungos Rhizopus e Aspergillus em nenhuma das amostras analisadas.

Figura 1. Porcentagem dos gêneros fungos detectados nas sementes das sete cultivares de pimentão (Capsicum annuum L.) comercializadas em Santarém, PA.

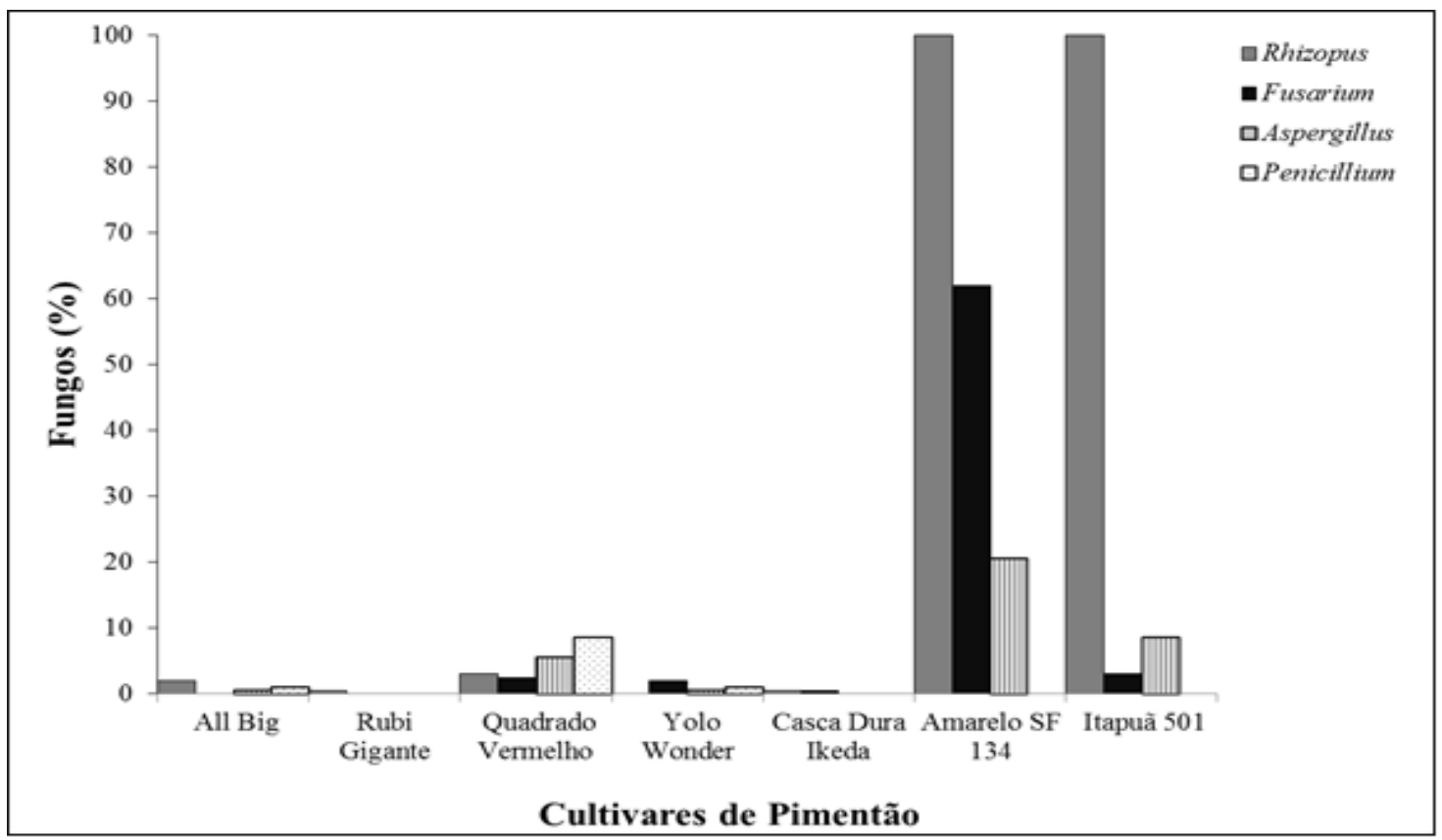

Muitos autores relatam a presença de Aspergillus, Fusarium, Penicillium e Rhizopus em sementes, como Torres et al. (1999), que observaram fungos do gênero Aspergillus em pequenas porções de sementes de tomate;
Barbiere et al. (2013) em estudos com aveia preta verificaram a presença de seis gêneros de fungos, entre esses, Aspergillus spp., Penicillium spp. e Rhizopus spp.; esse autores relatam ainda que este resultado pode 
ocasionar prejuízos na qualidade fisiológica das sementes, como também, comprometer o estande inicial da lavoura; Menten (1995) verificou uma redução drástica na germinação de sementes de feijão, provocada pela incidência de fungos Aspergillus spp. e Penicillium spp.; Barros et al. (2005) avaliando sementes de feijão também observaram a presença de Rhizopus sp., Penicillium sp., Aspergillus sp. e Fusarium solani f. sp. phaseoli, sendo que Rhizopus sp. foi o organismo com maior incidência nas sementes e, Moraes e Mariotto (1985) citam Rhizopus sp. como um dos responsáveis pela redução na germinação das sementes.

Os lotes de sementes das cultivares de pimentão All Big, Amarelo SF 134, Casca Dura Ikeda, Quadrado Vermelho e Rubi Gigante avaliados, apresentaram germinação de acordo com o informado pelo fabricante. No entanto, todos os lotes apresentaram vigor muito baixo, considerando-se a porcentagem de plântulas normais obtidas no teste de germinação;

As cultivares Amarelo SF 134 e Itapuã 501 apresentaram incidência fúngica em todas as suas sementes, sendo Aspergillus sp.; Penicillium sp., Fusarium sp. e Rhizopus sp. os gêneros de fungos encontrados;

O lote da cultivar Itapuã 501 apresentou a menor qualidade fisiológica e sanitária dentre as cultivares avaliadas;

De acordo com os resultados encontrados para os lotes das cultivares de pimentão avaliados nesse trabalho, a utilização dessas sementes poderia comprometer o estande inicial do plantio, considerando-se o baixo número de plântulas normais obtidos.

\section{REFERÊNCIAS}

AIMI, S. C.; ARAUJO, M. M.; MUNIZ, M. F. B.; WALKER, C. Teste de sanidade e germinação em sementes de Cabralea canjerana (Vell.) Mart. Ciência Florestal, v. 26, n. 4, p. 1361-1370, 2016. BARBIERI, M.; ÁVILA, V. S. de; MACIEL, C. G.; NOAL, G.; MUNIZ, M. F. B.; DÖRR, A. C. Qualidade sanitária de 
sementes de aveia preta cv. brs 139 (Avena strigosa SCHREB) submetidas ao envelhecimento acelerado. Revista Monografias Ambientais, v. 13, n. 13, p. 2828-2836, 2013.

BARROS, R. G; BARRIGOSSI, J. A. F; COSTA, J. L. da S. Efeito do armazenamento na compatibilidade de fungicidas e inseticidas, associados ou não a um polímero no tratamento de sementes de feijão. Bragantia, Campinas, v. 64, n. 3, p. 459-465, 2005.

BOTELHO, L. S.; MORAES, H. D.; MENTEN, J. O. M. Fungos associados às sementes de ipê-amarelo (Tabebuia serratifolia) e ipê-roxo (Tabebuia impetiginosa): incidência, efeito na germinação e transmissão para as plântulas. Summa Phytopathologica, v. 34, n. 4, p. 343-348, 2008.

BRASIL. Ministério da Agricultura, Pecuária e Abastecimento. Regras Para Análise de Sementes. Brasília, DF, 2009. 399 p.

COSTA, C. J. A importância do controle de qualidade de sementes. [s.l]: Embrapa Cerrados, 2008. 2 p.

DHINGRA, O. D.; ACUNA, R. S. Patologia de sementes de soja. Viçosa: UFV, 1997. 119 p.

FERREIRA, P. V. Estatística Experimental Aplicada à Agronomia. 3. ed. Maceió: Editora da Universidade Federal de Alagoas - EDUFAL, 2000. v. 1. $420 \mathrm{p}$.
FRANÇA-NETO, J. B.; KRZYZANOWSKI, F. C.; HENNING, A. A. A importância do uso de sementes de soja de alta qualidade. Londrina, PR: Embrapa Soja, 2010. 2 p. (Folder, n.1).

FRANZIN, S. M.; ROVERSI, T. O que é vigor de sementes? Centro de Ciências Rurais - Departamento de Fitotecnia Núcleo de Sementes - Universidade Federal de Santa Maria, 2002. Disponível em: <http://coral.ufsm.br/sementes/image s/vigor.pdf>. Acesso em: 03 de mar. 2017.

KIKUTI, A. L. P.; MENTEN, J. O. M.; MORAES, M. H. D.; OLIVEIRA. S. R. S. de. Interferência da assepsia em sementes de pimentão submetidas ao teste de envelhecimento acelerado. Revista Brasileira de Sementes, v. 27, n. 2, p. 44-49, 2005.

MAGUIRE, J. D. Spead of germinationaid in selection and evaluation for seedling emergence and vigour. Crop Science, v. 2, n. 2, p. 176-177, 1962.

MENTEN, J. O. M. Prejuízos causados por patógenos associados às sementes. In: MENTEN, J. $\bigcirc$. M. Patógenos em sementes: detecção, danos e controle químico. São Paulo: Ciba Abro, 1995. p. 115-136.

MORAES, S. A.; MARIOTTO, P. R. Diagnóstico da patologia de sementes de amendoim no Brasil. Revista Brasileira de Sementes, v. 7, n. 1, p. 4143, 1985OLIVEIRA, J. A.; PEREIRA, C. E.; GUIMARÃES, R. M.; VIEIRA, A. R.; 
SILVA, J. B. C. da. Efeito de diferentes materiais de peletização na deterioração de sementes de tomate durante 0 armazenamento. Revista Brasileira de Sementes, v. 25, n. 2, p. 20-27, 2003.

OLIVEIRA, S. R. S. de; NOVEMBRE, A. $\mathrm{D}$ da L. C. Teste de condutividade elétrica para as sementes de pimentão. Revista Brasileira de Sementes, v. 27, n.1, p. 31-36, 2005.

PEREIRA， C. E.; OLIVEIRA， J. A.; GUIMARÃES, R. M.; VIEIRA, A. R.; SILVA, J. B. C. da. Condicionamento fisiológico e revestimento de sementes de pimentão. Revista Ciência Agronômica, v. 36, n. 1, p. 74-81, 2005.

PEREIRA, R. B.; PINHEIRO, J. B.; CARVALHO, A. D. F. de Manejo do oídio em pimentão: um desafio em cultivo protegido. Embrapa: Comunicado Técnico 94, 2013.

POSSE, S. C. P; SILVA, R. F da; VIEIRA, H. D. Temperatura de armazenamento e desempenho de sementes hidratadas e osmocondicionadas de pimentão. Revista Brasileira de Sementes, v. 26, n. 1, p. 38-43, 2004.

RIBEIRO, C. S. da C.; CRUZ, D. M. R. Tendências de mercado: comércio de pimentão está em expansão. Cultivar Hortaliças e Frutas, v. 3, n. 14, p. 16-19, 2002.

RUIZ FILHO, R. R.; SANTOS, A. F. dos; MEDEIROS, A. C. S.; JACCOUD FILHO, D. S. Fungos associados às sementes de cedro. Summa Phytopathologica, v. 30, n. 4, p. 494-496, 2004.

SILVA, J. B. da; VIEIRA, R. D. Avaliação do potencial fisiológico de sementes de beterraba. Revista Brasileira de Sementes, v. 28, n. 2, p.128-134, 2006.

TALAMANI, V.; LIMA, N. S.; MENEZES, M. S.; SILVA, A. M. F.; SOUSA, R. C. de.; SILVA, L. M. da. Qualidade fisiológica e sanitária de sementes de feijão (Phaseolus vulgaris L.) produzidas por agricultores familiares em Sergipe. Aracaju: Embrapa Tabuleiros Costeiros, 2010.

TORRES, S. B.; PEIXOTO, A. R.; CARVALHO, I. M. S. de Qualidade sanitária e fisiológica de sementes de tomate da região do submédio São Francisco. Ciência e Agrotecnologia, Lavras, v. 23, n. 4, p. 825-829, 1999.

TORRES, S. B; MINAMI, K. Qualidade fisiológica de sementes de pimentão. Scientia Agricola, v. 57, n. 1, p. 109-112, 2000.

VIEIRA, R. D.; CARVALHO, N. M. Testes de vigor em sementes. Jaboticabal: FUNEP, 1994. 164 p. 